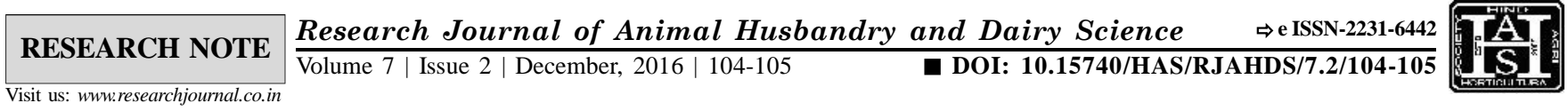

\title{
Study on the anti - Nasal schistosomal activity of Solanum xanthocarpum in bovine
}

\author{
U.UMADEVI AND T. UMAKANTHAN
}

\begin{abstract}
Fourteen cattle, non-descript breeds differing in age and sex, were taken in this study. History revealed frequent shaking of head, sneezing, nasal bleeding and scratching of nostrils against hard objects. Clinical and parasitological examination confirmed the presence of Schistosoma nasale in the nostrils. Two animals kept as control group without treatment and remaining 12 were intra nasally given the extract juice of Solanum xanthocarpum 3 drops twice daily for $7-10$ days. Control showed no recovery and the trial group was found 92 per cent effective on subsequent clinical and parasitological examinations.
\end{abstract}

KEY WORDS : Cattle, S.nasale, S. xanthocarpum

How TO CITE THIS PAPER : Umadevi, U. and Umakanthan, T. (2016).Study on the anti - Nasal schistosomal activity of Solanum xanthocarpum in bovine. Res. J. Animal Hus. \& Dairy Sci., 7(2) : 104-105 : DOI: 10.15740/HAS/RJAHDS/7.2/104-105.

Address for correspondence :

T. Umakanthan, Veterinary Surgeon, Veterinary Hospital, Sattur, VIRUDHUNAGAR (T.N.) INDIA

Email : sciencepot1614@gmail.com

Associated Authors':

U. Umadevi, Department of Botany Specialized with Plant Biotechnology, The Standard Fireworks Rajaratnam College for Women, Sivakasi, VIRUDHUNAGAR ( T.N.) INDIA Email : dr.umadeviumakanthan@gmail.com 